\title{
E-commerce System for the Sales Process in the Company: A Systematic Review
}

\author{
Keyla Huacre, Alfredo Daza, Elvin Mejia \\ Professional Academic School of Engineering System Cesar Vallejo, Lima, Peru \\ ${ }^{1}$ khuacrel@ucvirtual.edu.pe; ${ }^{2 a d a z a v e @ u c v i r t u a l . e d u . p e ; ~}{ }^{3 e m e j i a p 1 @ u c v i r t u a l . e d u . p e}$
}

\begin{abstract}
E-commerce in these times has become the most important need for the growth of buying and selling via the internet; as it comes to make a faster system to make all kinds of purchases, it is also seen that sales are made by social networks which can not get a control process or improvement and to achieve these strategic objectives and opportunities for each organization, the need to develop e-commerce systems according to the needs of the organization is seen. The objective of this research is to make a systematic review, as well as the methodology that is applied when implementing an E-commerce System. To achieve this objective, a deep research has been done where the scientific evidence related to the case study has been found with a large number of scientific articles and a selection according to the inclusion and exclusion points of view for the search of the information, thus having the research questions.
\end{abstract}

Keywords: E-commerce, scrum, agile methodology, seo, sales. 


\section{Introduction}

The electronic commerce comes to make a new mode of income in families and businesses, whether global, regional, national and local level, covers a lot in the economy, because through websites you can get information to see the products and qualities, prices and services that we can get, delivery dates, searches, etc.

E-commerce includes the process of buying and selling goods and services through the use of modern communication technology and the Internet. The success of this type of transactions depends largely on the website where the sale is made. Online e-commerce platforms are complex applications that perform multiple functions (Guillermina, 2019). The application of business-to-business e-commerce in developing countries is different from developed countries because developing countries still have deficiencies in terms of infrastructure, finance, law and other things needed to develop e-commerce (Huang et al., 2020). In this sense, an analysis of the E-commerce system is important to ensure an efficient sales process.

On the other hand, sales processes have been relatively scarce, considering the amount of time and money that is invested in this application (Leovin et al., 2020), being a service system provides us with pre-sales to see the current state of the company and post-sales that focuses on improving the quality of service for the future of companies (Rodriguez et al., 2018). There is also the e-commerce website, as it is used to make online purchases from the consumer, make online transactions between buyer and seller (He and Yin, 2021).

In general, the use of E-Commerce system for the improvement of the sales process has been advancing and is one of the most important transaction channels. Individuals, businesses and all governments are involved in e-commerce transactions (Arkadiusz, 2017).

Nowadays, companies suffer from sales process control problems due to the lack of an E-commerce system to be able to keep a good control and help to improve every part of the sales process. Companies also offer the possibility to view inventories and prepare customer orders (Wang, 2020). E-commerce also includes not only in buying and selling, but also in various processes within the organization.

Information seeking behavior always appears in Pre-exchange, when a person clicks the mouse and opens IE, Visit the website. Perhaps this information is attractive and stimulating. In addition, the information to be known is usually generated during the learning phase. Medium of exchange. Compared to offline shopping, consumers want to buy goods and their purchase value. Your response and participation will enhance their judgment, preference and behavioral judgments, information and choices will be shown. Different behavioral influences (such as purchase, confirmation, repurchase, even satisfaction) always appear in Switch to the middle or the reverse (Xiong, 2011).

The success and steady development of commerce must be based on in scientific knowledge of the environment and its solutions Scientifically tested to evaluate 
efficiency Use e-commerce technology. Business expenses, when e-commerce technologies are used, they are usually less Cost more than traditional commerce because they do not need to invest Equip the store or hire people to work in the store. Traditional stores; however, the cost seems to have increased Due to the implementation and maintenance of technology E-commerce and product delivery (Burinskienè, 2017).

After the analysis of the various documentations on $\mathrm{E}$ commerce for the improvement of the sales process, this paper aims to answer the following question: What studies exist for the improvement of sales processes with the use of the $\mathrm{E}$ commerce system? What methodologies exist for the development process of an Ecommerce system? And what tools exist for the positioning of a web system? To provide an answer to the proposal, a systematic review is proposed that will comprise of literature from the periods of 2016 to 2021.

In addition, by developing this research, it motivates to perform a systematic literature review, mainly to know the main software development models for inventory control in organizations.

Thus, it was necessary to apply the literature review as a methodology to obtain different results, through bibliographies related to studies of projects implemented by other authors that use systems or web applications, as well as studies related to inventory control in organizations.

The present research is divided into five sections. The next section covers the methodology used for the systematic review by posing the research questions, in the third section, the results found and the review of the scientific evidence. In the fourth section, the discussion of the findings. Finally, in the last section is the conclusion of the research.

\section{Methodology}

To conduct the review, we will use a methodological approach, which is based by Kitchenham and Charters (Kitchenham and Charters, 2007), therefore, this guide consists of three important aspects for the review. In the following, the steps of the proposed methodology will be described along with the research questions that are intended to be answered through this study:

Planning the review: In this aspect it is important to carry out the need to specify the review by introducing the research questions.

Conducting the review: In this aspect the studies are selected, according to the perspective of inclusion and exclusion.

Results of the review: In this aspect the statistics and analysis of the selected articles are shown.

\subsection{Planning of the review}

The following repositories of indexed scientific articles were consulted for the 
review: Scopus, Proquest, Ebscohost, IEEE Xplore, Wiley Online Library, Emerald insight . The research questions for information search are as follows:

Q1: What studies exist for the improvement of sales processes with the use of the E commerce system?

Q2: What methodologies exist for the development process of an E-commerce system?

Q3: What tools exist for the positioning of a web system?

\subsection{Conducting the review}

The search process was initiated by applying the following search strings in repositories of journals and articles scientific indexed articles in order to obtain potential results for the research:

Table 1. Literature search string

\begin{tabular}{|c|c|}
\hline Research question & Search string \\
\hline $\mathrm{P} 1$ & $\begin{array}{l}\text { KPIs for sales process improvement in the use of the E Commerce } \\
\text { system }\end{array}$ \\
\hline $\mathrm{P} 2$ & $\begin{array}{l}\text { Agil, Scrum, Rup, XP for the development process of an E- } \\
\text { commerce system. }\end{array}$ \\
\hline P3 & $\begin{array}{l}\text { Seo Optimization through Google for the positioning of a web } \\
\text { system, Laravel }\end{array}$ \\
\hline
\end{tabular}

The results obtained from potential articles were filtered by applying the following inclusion and exclusion criteria.

Table 2. Inclusion and exclusion criteria

\begin{tabular}{|c|c|}
\hline Inclusión & Exlusión \\
\hline Related items from 2017 to 2021. & \\
\hline $\begin{array}{l}\text { Studies related to indicators for the sales } \\
\text { process of an E-commerce system. }\end{array}$ & $\begin{array}{c}\text { Articles that do not meet the inclusion } \\
\text { criteria. }\end{array}$ \\
\hline $\begin{array}{l}\text { Studies related to the Scrum methodology } \\
\text { for the development process of an E- } \\
\text { commerce system. }\end{array}$ & $\begin{array}{c}\text { Posters, newsletters, theses, letters, } \\
\text { books. }\end{array}$ \\
\hline $\begin{array}{c}\text { Studies related to Seo optimization } \\
\text { through Google for the positioning of a } \\
\text { web system. }\end{array}$ & $\begin{array}{l}\text { Articles that do not contain an } \\
\text { identification code (DOI, ISSN). }\end{array}$ \\
\hline
\end{tabular}


A complete review of the articles collected according to the aforementioned points was carried out, finally reaching a reduced group of articles, thus obtaining a reduced group of articles selected to answer the research questions. Several articles were excluded as they did not meet the detailed criteria. A figure is presented below to explain the search process carried out.

\subsection{Results of the review.}

Of 65 scientific publications found through the search chain with the potential to solve the research question, 36 scientific publications that passed the inclusion and exclusion criteria were obtained. However, after a complete reading of the documentation, 18 publications were selected to answer our research questions.

Below are the representative percentages for each database.

Table 3. Potential, filtered and selected items

\begin{tabular}{|c|c|c|c|c|}
\hline Repositories & $\begin{array}{c}\text { Potencial } \\
\text { Articles }\end{array}$ & $\begin{array}{c}\text { Filtered } \\
\text { Articles }\end{array}$ & $\begin{array}{c}\text { Selected } \\
\text { articles }\end{array}$ & Percentage \\
\hline IEE Explore & 26 & 15 & 6 & $40 \%$ \\
\hline Scopus & 14 & 4 & 4 & $20 \%$ \\
\hline Scielo & 7 & 6 & 0 & $0 \%$ \\
\hline Proquest & 7 & 3 & 5 & $25 \%$ \\
\hline Ebscohost & 8 & 4 & 0 & $0 \%$ \\
\hline $\begin{array}{c}\text { Wiley Online } \\
\text { Library }\end{array}$ & 2 & 2 & 2 & $10 \%$ \\
\hline Emerald insight & 1 & 1 & 1 & $5 \%$ \\
\hline Total & $65 \%$ & $36 \%$ & $18 \%$ & $100 \%$ \\
\hline
\end{tabular}

\subsection{Results fund}

From the literature review through different of mentioned database, a total of 18 articles related to the research questions were identified, the results of which are shown below detailing the author and their respective conclusion of each selected article.

\subsection{Results of e-commerce studies using web-based systems or applications.}

According to Dong (Dong, 2021) in his article mentions that the development and improvement of mobile network communication technology and credit security and confidentiality systems, e-commerce has gradually developed in the direction of mobile e-commerce. Wired business transactions have been converted into wireless mobile business transactions. The network infrastructure has been further improved. At the same time, the optimization and improvement of the secure online payment system have solved the problems of e-commerce security authentication and 
payment methods.

According to Sulova (Sulova, 2019), in their article mentions that the evaluation of e-commerce websites has a great influence on the growth of network marketing sales and revenue. It is part of the overall e-commerce analysis process, which includes all system data analysis activities performed to improve the business performance of online sales companies. Their study concluded that, the evaluation system can perform a comprehensive analysis of an online store's availability, content and functions, not just view simple statistics on its attendance rate.

According to Cristobal, Montegut and Daries (Eduard et al., 2017), in their article mentions that the continuous development of the website, this movement is reflected in different stages of development from inception (promotion), integration (provision) to final maturity (processing). The complexity and functional level of the website is added to the model. This level of consolidation reflects the evolution of the company from a static Internet presence to a dynamic website by increasing the level of interactivity, including the integration of value chains and innovative applications to add value through information management and more powerful functions.

According to Whyte, W(Whyte, 2001), in their article mentions that the ecommerce platform is conceptual, not real. As we shall see, it consists of parts of a multi-level computer architecture, assembled on many hardware and software platforms. In fact, some parts E-commerce models are sometimes hosted on the user's terminal. Not just on the provider's server. But the concept of an e-commerce platform is useful because it allows us to consider the necessary elements Elements needed to support e-commerce.

According to Laosethakul, K. y Boulton, W. (Laosethakul and Boulton, 2007) in their article mentions that the e-commerce as "application of information technology solutions" Help define and formulate new strategies to solve business problems. "Companies can derive many benefits from e-commerce. For example, SMEs can benefit from 24-hour availability of services, direct contact with customers, meeting their needs and promoting business development. 24-hour service, direct contact with customers, meeting their needs, promoting customer relations and information exchange, as well as increasing sales and increasing productivity to increase sales and increase productivity and profitability.

According to Alzahrani, J (Alzahrani, 2019) in their article mentions that the Thai government began drafting six laws on e-commerce in 1998: the Electronic Transactions Act, the Electronic Signature Act, the Cybercrime Act, the Data Protection Act, the Electronic Funds Transfer Act and the Universal Access Act. The government hopes that these new laws will improve the security of e-commerce and give consumers and businesses more confidence in the viability of B2B and B2C online transactions. 


\subsection{Results of Types of development frameworks or methodologies}

According to Saeedi and Visvizi (Saeedi and Visvizi, 2021) talks about agile methods Agile methodology, in the Agile Manifesto, the values and principles are universal and can be used in many ways. Or frameworks such as Scrum, Extreme Programming (XP) Crystal, Kanban and other methods. In this case, Scrum is the most popular agile framework in the industry. Due to its importance, within the agile framework it belongs to the category of skills most needed in the working world. The framework is not only applicable to software project management, but it is a simple and lightweight framework. Framework for the development of complex products. One of its main features: transparency, inspection and adaptability. Compared to other agile methods, Scrum provides Projects with fixed interval iterations are called sprints. and also has three roles, five Scrum events, artifacts and rules connect them.

According to Srivastava, S. Bhardwaj and S. Saraswat (Srivastava and Saraswat, 2021) in their article mentions that Scrum has the capability to cater to the needs of thousands of projects and can very well be scaled to large numbers. It is the small aspects of its implementation that are having significant problems such as lack of automation in workflow and testing workflow, better management support and lack of availability of experienced team workers.

According to Apoorva, Sukriti and Shipra (Faniran et al., 2017) in their article, they mention that the Scrum methodology is a customized way of working on different projects that have a variety of requirements and advantages such as the selection of requirements for sprints, as well as analyzing their relevance and improvement for good project development and scalability. Its objective of the Sprint cannot be changed during a Sprint, but every increment, the product owner adds new features to the project. Scrum has become the face of agile and often terms, which allows the product owner to initiate a project. About $82 \%$ of respondents use Scrum and $11 \%$ are piloting Scrum.

According to Pereira (Pereira, 2016) in his article he mentions that agile methods also divide software development into iterations, seek risk reduction for the project and deliver a working version (release) of the product to the customer at the end of each iteration. This leads to better interaction between the customer and the development team. They stand out because they prioritize the human factor in project development, promote development team interaction and partnership with customers. The RUP has a better defined structure making a better division of the project in relation to activities, tasks, roles and responsibilities and generates a collection of artifacts that are used as input and output products of the processes.

According to Almeida (Almeida and Júnior, 2019) in his article he mentions that as the development team promises to provide fast, consistent and high quality deliverables, Scrum has emerged in software development companies, and more and more Scrum teams face challenges in selecting activities to perform. The results 
of this research finally formed an algorithm that provides an analysis of Sprint activities to create and a prototype to implement, which will be confirmed by the Scrum development team.

According to Sharma (Sharma et al., 2016) regarding Extreme Programming (XP), it focuses on creating 5 to 15 members and follows 12 practices that are related. In addition, XP is specified in delivering executable code and test drivers rather than working on the requirements documentation and paper-based design part. The creation of the small development grouping helps to prevent the documentation part, the communication between people can take place effectively. But, as the development organization grows, the time spent sharing product knowledge and training people increases and often makes XP inadequate. XP suggests a set of software development practices to achieve productivity and quality.

\subsection{Results of Types of Frameworks for web development}

According to VM Patil and AV Pati (Patil and Patil, 2018) in their article mentions that to improve ranking or visibility in search engines like google, yahoo search engine optimization is effective technique. By improving the rank and visibility in search engine it helps to improve the user interaction with the website. This paper discusses the various techniques to improve visibility and rank in search engine result. Maximum focus of this paper on off-page SEO technique. This analysis especially off-page SEO technique with on-page SEO technique will help to improve the search engine result.

According to A. Dalvi and R. Saraf (Dalvi and Saraf, 2019) in their article mentions that SEO is an integral process to maintain website visibility in search engines. It is important for all organizations to seriously consider SEO. From our work, we can conclude that there is no conscious attention to SEO in the education sector even in engineering college websites. Even the most well-known engineering colleges have not been able to incorporate SEO. Occasionally, the website of these colleges performs one or two SEO parameters, but no knowledge is reflected towards the inclusion of SEO techniques in the websites. We conclude that more efforts are required in the direction of opting knowledge towards SEO.

According to Xiaoxue, Qiao, Xin, Zhenchang, Lingfeng, Lo. (Qiao et al., 2018) in their paper mention that a semi-automated approach is proposed to summarize bug reports in Ubuntu and identify the common problems of different packages. We conducted an empirical study on a total of 240,097 bug reports collected in Ubuntu. Through manual summarization, we identified 3 common problems commonly seen in different Ubuntu packages, namely Graphical User Interface (GUI), Maintenance, and Lack of time. Next, we ranked the top 100 packages with the highest number of problems.

According to Yadav, Shri (Yadav et al., 2019) in his artiche he mention that the LARAVEL is one of the top most used PHP frameworks. As networks are growing 
everyone wants their network to be big and large and for that, he or she needs to connect with customers by his or her websites that can provide information about his or her company and their products. With the traditional approach to website designing, it takes time and other issues, for such problems frameworks, are invented. PHP frameworks provide codes which are already coded; we just have to the module this information according to our requirements. Web designing with Laravel framework is very easy and simple, but one should know the basics of PHP to understand the Framework structure. The proposed model is to design an ecommerce website with the help of PHP framework-LARAVEL. This report designs a simple Laravel based website and for this first, we'll see what the requirements are for the framework.

According to Lopez, Medina and Alcazar (López-Pimentel et al., 2021) in their article they mention that PHP and JavaScript Server (Node.js) are the latest serverside programming languages that we use in these courses. Note that these languages are not taught in the same course, because in the back-end part of the project, students are free to choose the programming language; this has led some students to choose Node.js and .NET. In this sense, we observed that only $10 \%$ of the students prefer to use technologies other than those recommended in class.

According to Ali Gunawan (Gunawan, 2020), The framework with Laravel is built with the concept of MVC (Model, View, Controller) and a PHP framework. Laravel Use these tools to help improve software quality Reduce development and maintenance budget Maintenance and time savings.

After the text edit has been completed, the paper is ready for the template. Duplicate the template file by using the Save As command, and use the naming convention prescribed by your conference for the name of your paper. In this newly created file, highlight all of the contents and import your prepared text file. You are now ready to style your paper; use the scroll down window on the left of the MS Word Formatting toolbar.

\section{Analysis of results}

Based on the results found in the literature review we have the following analysis:

\subsection{Analysis of results of Tools and technologies that exist for $\mathbf{E}$ - commerce system.}

Next, the analysis of the results obtained from the literature review of the studies is performed, as indicated in Table IV.

Table 4. Analysis of Results of Tools and Technologies That Exist For E-commerce

\begin{tabular}{|c|c|c|}
\hline \multicolumn{3}{|c|}{ System. } \\
\hline Reference & E-commerce & Web site \\
\hline Dong, 2021 & & $\mathrm{x}$ \\
\hline Sulova, 2019 & & $\mathrm{x}$ \\
\hline
\end{tabular}




\begin{tabular}{|c|c|c|}
\hline Eduard et al., 2017 & & $\mathrm{x}$ \\
\hline Whyte, 2001 & $\mathrm{x}$ & \\
\hline Laosethakul and Boulton, 2007 & $\mathrm{x}$ & \\
\hline Alzahrani, 2019 & $\mathrm{x}$ & \\
\hline Total & 3 & 3 \\
\hline Percentage & $27.7 \%$ & $27.7 \%$ \\
\hline
\end{tabular}

When analyzing the results found for the e-commerce studies using web systems or applications, it can be observed that the authors of the articles reviewed as a whole are balanced, since 1 article was found on the importance of implementing an electronic system. From the percentage point of view, the percentage of related studies for each of them was $13.3 \%$.

In response to research question 1 , it can be stated that 2 studies were applied for two technological topics (e-commerce, website).

\subsection{Analysis of Types of development frameworks or methodologies}

The following is the analysis of the results obtained from the literature review of the types of development frameworks or methodologies, as shown in Table V.

Table 5. Analysis of results types of development frameworks or methodologies

\begin{tabular}{|c|c|c|c|c|}
\hline Reference & Agil M & Scrum & Rup & XP \\
\hline $\begin{array}{c}\text { Saeedi and } \\
\text { Visvizi, 2021 }\end{array}$ & X & & & \\
\hline $\begin{array}{c}\text { Srivastava and } \\
\text { Saraswat, 2021 }\end{array}$ & & X & & \\
\hline $\begin{array}{c}\text { Faniran et al., } \\
\text { 2017 }\end{array}$ & & $\mathrm{X}$ & & \\
\hline $\begin{array}{c}\text { Pereira, 2016 } \\
\text { Almeida and } \\
\text { Júnior, 2019 }\end{array}$ & & $\mathrm{X}$ & & \\
\hline $\begin{array}{c}\text { Sharma et al., } \\
\text { 2016 }\end{array}$ & & & & \\
\hline \begin{tabular}{c} 
Percentage \\
\hline
\end{tabular} & $16.7 \%$ & $50 \%$ & $16.7 \%$ & $16.7 \%$ \\
\hline
\end{tabular}

When analyzing the results found on the basis of the existing methods and studies, it is observed that the authors of the articles reviewed mostly apply the Scrum methodology, in three articles they make a model based on Scrum, one on RUP, Agile Methodology and XP. Therefore, we can take as a reference the reviewed models and select specific components, to propose a systematic model. From this percentage point of view, the Scrum method is the most used with $50 \%$, the RUP 
method with $16.7 \%$, the XP methodology with $16.7 \%$ and the agile methodology with $16.7 \%$.

Responding to the research question $\mathrm{N}^{\circ} 2$, it can be indicated that 4 methodologies have been found for the e-commerce system.

\subsection{Analysis of Results of Types of Frameworks for web development}

When analyzing the results found on the basis of development technologies for web systems, it can be observed that the authors of the articles reviewed mostly consider Laravel as web development, and fewer articles consider SEO, PHP, and Ubuntu. From the percentage point of view, Laravel has $33.3 \%$, PHP has $16.7 \%$ respectively, SEO has $33.3 \%$ and Ubuntu has $16.7 \%$.

Responding to the research question $\mathrm{N}^{\circ} 3$, it can be indicated that 4 types of technologies have been found for the development of a web system.

Table 6. Analysis of results types of frameworks for web development

\begin{tabular}{|c|c|c|c|c|}
\hline REFERENCE & SEO & UBUNTU & $\begin{array}{c}\text { LARAVE } \\
\text { L }\end{array}$ & PHP \\
\hline $\begin{array}{c}\text { Patil and Patil, } \\
2018\end{array}$ & $\mathrm{X}$ & & & \\
\hline $\begin{array}{c}\text { Dalvi and Saraf, } \\
2019\end{array}$ & $\mathrm{X}$ & $\mathrm{X}$ & $\mathrm{X}$ & \\
\hline $\begin{array}{c}\text { Qiao et al., 2018 } \\
\text { Yadav et al., } \\
2019\end{array}$ & & & $\mathrm{X}$ & $\mathrm{X}$ \\
\hline $\begin{array}{c}\text { López-Pimentel } \\
\text { et al., 2021 }\end{array}$ & & $16.7 \%$ & $33.3 \%$ & $16.7 \%$ \\
\hline $\begin{array}{c}\text { Gunawan, 2020 } \\
\text { Percentage }\end{array}$ & $33.3 \%$ & & & \\
\hline
\end{tabular}

\section{Conclusions}

The following conclusions have been identified regarding the methodical review of the literature and we indicate that:

It was demonstrated that there are 18 articles that are related to the research questions considering the inclusion and exclusion factors, in addition to the search protocols. Concluding that there are studies that present a similar problem with great significance to provide solutions to the problems of E-commerce system management in companies. 
In this study it has been identified that the Scrum methodology has the capabilities to meet the needs of thousands of projects where it can be scaled to large quantities, thus seeking to reduce risks in the project between the client and the development team, in this way to deliver quality results.

In the present study it has been identified that the SEO tool improves the rank and visibility in the search engine as it helps to improve the user interaction with the website, this requires that companies can opt efforts to opt with SEO in their web pages.

\section{References}

Almeida, O. D., \& Júnior, G. I. (2019). Uma Solução Algorítmica Para Projetos De Ti Utilizando Metodologia Ágil Scrum: Um Estudo De Caso. Revista Inovação, Projetos E Tecnologia, [S. L.], 7(1), 80-91.

Alzahrani, J. (2019). The impact of e-commerce adoption on business strategy in Saudi Arabian small and medium enterprises (SMEs), Review of Economics and Political Science, 4 (1), 73-88.

Arkadiusz, K. (2017). Fulfillment Service In E-Commerce Logistics. Logforum, 13(4), Oct, Ebscohost, 429-438.

Burinskienè, A. (2017). E-commerce in Activity of Trade Enterprises. Journal of System and Management Sciences, 7 (2017) (1), 1-14.

Dalvi, A. \& Saraf, R. (2019). Inspecting Engineering College Websites For Effective Search Engine Optimization, 2019 International Conference On Emerging Technologies In Engineering (Icnte), 1-5.

Dong, Z. B. (2021). Mobile E-Commerce Platform And Analyzing Its Impact On ECommerce Logistics Customer Satisfaction [Online]. Complexity, 2021 Proquest Central. Issn 10762787.

Eduard, C., Yolanda, S., \& Natalia, D. (2017). Cooperativism 2.0: Internet presence and e-commerce development in olive cooperatives in Catalonia. REVESCO. Journal of Cooperative Studies. 124.

Faniran, V., Badru, A., \& Ajayi, N. (2017). Adoption Of Scrum As An Agile Approach In Distributed Software Development: A Literature Review, 1st International Conference On Next Generation Computing Applications (Nextcomp), 36-40. 
Guillermina, B. (2019). Research methodology. Serie integral por competencias. Mexico: Editorial Patria (3rd Edition). ISBN:978-607-744-748-1.

Gunawan, A. (2020). Selection of Web-Based Framework for System Development using AHP (Analytic Hierarchy Process) Method in PT. XYZ.

He, J., \& Yin, X. (2021). Innovation Path Of Internet Enterprise Business Model Based On E-Commerce. Journal Of Physics: Conference Series, 04, 1852(4) Proquest Central. Issn 17426588.

Huang, Y. D., Chai, Y. T., Liu, Y., \& Shen, J. P. (2020). Next generation ecommerce platform architecture.

Kitchenham, B., \& Charters, S. (2007). Guidelines for performing Systematic Literature Reviews in Software Engineering, Durham.

Laosethakul, K., \& Boulton, W. (2007). Factores críticos de éxito para el comercio electrónico en Tailandia: influencias culturales y de infraestructura. The Electronic Journal of Information Systems in Developing Countries, 30: 1-22.2007.

Leovin, A., Beng, J. T., \& Dewayani, E. (2020). Business-to-business e-commerce sales system using Web-based Quotation: a case study on X.2020 company.

López-Pimentel, J. C., Medina-Santiago, A., Alcaraz-Rivera, M., \& Del-Valle-Soto, C. (2021). Sustainable project-based learning methodology adaptable to technological advances for web programming. Sustainability, 13(15), 8482.

Patil, V. \& Patil, A. (2018). Seo: On-Page + Off-Page Analysis, International Conference On Information, Communication, Engineering And Technology Of 2018 (Icicet), 1-3.

Pereira, D. J. (2016). Comparison between software development methodologies based on Rup and Xp methods. Journal Of Applied Technology, 5(3) (September 2016): 46-52.

Qiao, X. X., Xin, Z. C., \& Lo, L. F. (2018). Characterizing Common And DomainSpecific Package Bugs: A Case Study On Ubuntu[En Línea]. [23-27 July 2018].

Rodriguez, M., Peterson, R. M., \& Krishnan, V. (2018). Impact of CRM technology on sales process behaviors: empirical results from US, Europe, and Asia. Journal of Business-to-Business Marketing, [s. 1.], 25(1), 1-10. 
Saeedi, K., \& Visvizi. A. (2021). Software Development Methodologies, HEIs, and the Digital Economy.

Sharma, R., Kumar, S., \& Gupta, K. (2016). strategies for Web Application Development Methodologies, 160-165.

Srivastava, S. B., \& Saraswat, S. (2021). Scrum Model For Agile Methodology[Online]. International Conference On Computing, Communication And Automation (Iccca), 2017, 864-869.

Sulova, S. (2019). Un sistema para la evaluación de sitios web de comercio electrónico. Sofía: Surveying Geology \& Mining Ecology Management (Sgem)[En Línea]. Proquest Central.

Wang, C. S. (2020). Research on Factors Influencing Consumer Satisfaction In Agricultural E-Commerce Supply Chain. [Online].Issue 1,1607.

Whyte, W. (2001). The Retail (eCommerce) Server. In Enabling eBusiness, W. Whyte (Ed.).

Xiong, X. Y. (2011). The chain of consumer experience based on interactivity in ebusiness. Journal of System and Management Sciences, 1 (2011) (5), 42-48.

Yadav, N., Rajpoot, D. S., \& Dhakad, S. K. (2019). Laravel: A Php Framework For E-Commerce Website[En Línea]. Piscataway: The Institute Of Electrical And Electronics Engineers, Inc.(Ieee). 